\title{
Schoolgirls' Knowledge of, and Efforts against Risky Sexual Activity: The Needs for Sex Education in Schools
}

\author{
Budeba Petro Mlyakado ${ }^{1, *}$ \\ ${ }^{1}$ Department of Educational Psychology, Dar es Salaam University College of Education, Dar \\ es Salaam, Tanzania \\ *Correspondence: Department of Educational Psychology, Dar es Salaam University College \\ of Education, P. O. Box 2329, Dar es Salaam, Tanzania
}

Tel: 255-755-368-329 E-mail: mlyakado@yahoo.co.uk

Received: December 7, 2012 Accepted: January 16, 2013 Published: February 19, 2013

doi:10.5296/ije.v5i1.2825 URL: http://dx.doi.org/10.5296/ije.v5i1.2825

\begin{abstract}
This study explored schoolgirls' knowledge of sexual activity and their efforts against risky sexual activity including unplanned-premarital-pregnancies in Bagamoyo district and Shinyanga district, in Tanzania. Schoolgirls in Tanzania are under considerable pressure to engage in sexual activity unrealistically, and consequently drop out of school due to pregnancy. Using questionnaire, covert observation, and focus group interviews to 96 schoolgirls, the study revealed that schoolgirls have the basic knowledge of sexual activity, and most of them are sexually active. Schoolgirls practise sexual activity but they have less negotiating power on safer sex and preventing themselves from pregnancy and HIV infections. They are also at considerable risks of sexual violence or abuse from their teachers and the 'sugar daddies' through sexual exploitation. The study, then, underscores the provision of sex education to students and the whole community as well as rethinking on how to bring up the youths in acceptable sexual behaviours.
\end{abstract}

Keywords: sexual activity; unplanned-premarital-pregnancy; schoolgirls; sex education 


\section{Introduction}

Schoolgirls' pregnancy and poor academic performance have been the topics of discussion of many education stakeholders. As it was reported in the Daily News (Wednesday, $21^{\text {st }}$ April, 2010), the trend showed that, in a number of Tanzanian parliamentary sessions, issues of schoolgirls' pregnancy and dropping out of school due to pregnancies are discussed. Statistics from the Ministry of Education and Vocational Training (MoEVT) indicates that in 2010 a number of secondary school students dropped out of school due to pregnancy reasons were 6345 (MoEVT, 2010). This is a worrying situation, especially for the academic, social and economic developments of adolescents. In addition, parents fear about the health of their children during this era of HIV/AIDS. HIV/AIDS refers to acquired immune deficiency syndrome (AIDS) a sexually transmitted infection that is caused by the human immunodeficiency virus (HIV), which destroys the body immune system (Santrock, 2006).

Studies show that, many adolescents are susceptible to negative outcomes associated with sexual behaviour, particularly, those who initiate sexual intercourse at an early age, have many sex partners, or engage in unprotected sex because these behaviours put one at risks for sexually transmitted infections (STIs), including HIV (Walcott, Meyers, \& Landau, 2007).

Adolescent pregnancy and childbearing are matters of substantial national concern, yet, the analysis and description of these phenomena, much less prescriptions for altering present trends, are highly controversial (Hayes, 1987). Currently, the cultural overlapping has left adolescents, in Tanzania for example, confused or undecided whether to abide to their traditions and customs or to fall under the cultural imperialism-the western ways of living-especially, those who get access to multimedia like televisions, internets, and newspapers. Sexual behaviours and practices are also changing day after day. For instance, there is an increase of cross-generational sex that involves the relationships between older men [sugar daddies] and young women-below age 20-although some involves relationship between older women [sugar mammies] and young men (Hope, 2007). These sexual relationships signify sexual exploitation in our society.

Sexual relationships among students are on increase and common in schools (Mgalla, Schapink, \& Boerma, 1998). Students practise sexual activity, which has resulted into increased cases of schoolgirls' pregnancies, poor academic performance, and eventual drop out of schools. The reasons for the increased students' sexual activity practice have been associated with poor parenting; students' desire to satisfy their selfish, primitive sexual derives (Kelly, 2001; Santrock, 2006). Equally, some studies suggest economic factors-poverty in particular-and sexual exploitation done by adults to adolescents particularly schoolgirls (Evans, 2002; Philemon \& Kessy, 2008). Further, in adolescents' sexual development, as in many other aspects of their growth, they often experience confusion, fear and misunderstandings about their bodies and emotions (Kelly, 2001).

Studies on adolescents' sexuality reveal that, many adolescents obtain sexual information haphazardly (Shemdoe, 2005), and there is a considerable disagreement regarding how best adolescents can be prepared to become sexually healthy and responsible adults (Baber, 2005). It is all too easy to avoid or to deal only obliquely with issues that arouse so many 
deep-seated emotions and convictions (Hayes, 1987). Additionally, Kelly (2001) cements on the same that, for sometimes, experts have focused on the dangers and risks of adolescents' sexual activities, often overlooking the fact that many adolescents feel a desire for sexual pleasure and are planning to act on that desire when circumstances make it possible.

The fact that there are no common ways to bring up adolescents on sexual matters, this calls for an effective sex education in schools, where most adolescents spend a long part of their adolescence. Mkumbo and Tungaraza, (2007) believe that sex and relationship education can effectively bring changes to adolescents' sexual behaviours, if given chance in schools. Though, education is equally important to both men and women, limited education heightens the risks for women, undermining their self-confidence, status, and ability to find employment and other opportunities (Philemon \& Kessy, 2008). This knowledge gap necessitated for this study to underscore the knowledge and efforts of schoolgirls on issues of sexual activity.

\subsection{Statement and Justification of the Study}

First, HIV/AIDS has remained a most striking pandemic in the world and the mostly affected area being the Sub-Saharan Africa. No cure has been discovered so far, which put the world population at risk. There is no cure for HIV at this time, and the ART-Antiretroviral Therapy-can't cure HIV, as well the anti-HIV medications only help people infected live longer, healthier lives (AIDS info, August, 2012), but does not cure HIV/AIDS. Therefore, nobody can claim in this situation to be safe, because danger may happen at any time and an unexpected moment. In fact, ignorance has been the most possible and great catalyst of the spread of HIV infection to many people. And, the worst thing is, studies have shown that there are unequal gender relations that drive the epidemic (Campbell \& MacPhail, 2002; Philemon \& Kessy, 2008).

Second, it is fascinating that since the first report of the cases of HIV infection there has not happened any time when the spread has stopped. Despite the increased strategies to combat HIV/AIDS pandemic, its spread has never stopped. The fact, which cannot be denied, is that, the number of people living with HIV/AIDS is increasing day after day. Statistics in Tanzania for example shows that in 1983, the first three AIDS cases were reported in Kagera region; three years later, 1986, all the regions in Tanzania Mainland had reported AIDS cases; and by the end of 1999 there were some 600,000 cases of HIV/AIDS (The United Republic of Tanzania - Prime Minister's Office, 2001). Worse enough, young people are more affected. It was estimated that more than 60 percent of all new infections in Tanzania occurred among young people aged 15 to 24 (Tanzania Commission for AIDS, National Bureau of Statistics \& ORC Macro, 2005 cited in Mkumbo, 2009). By the end of 2007, it was estimated that 1.4 million people were living with HIV and the HIV prevalence was at 6.5 among adults aged 15 to 49 (UNAID/WHO, 2007 cited in Mkumbo, 2009) though the rate has slightly decreased to 5.7 as per 2007-2008 (TACAIDS, et al., 2008).

Third, schoolgirls' pregnancy has been the song of the day. Youths, in schools, are in danger and at risk of unplanned-premarital-pregnancy and poor academic performance due to their involvements in sexual activity, at that teen age. Apart from being in danger and at risk of 
teenage pregnancy and poor academic performance, they are equally vulnerable to STIs, including HIV due to excessively early or unsafe sexual activity (Kelly, 2001; Walcott, Meyers, \& Landau, 2007). Oftentimes it has been forgotten that adolescence is a time where experimentation with sexual activity is normal and there are safe and developmentally appropriate ways in which this may occur (Santrock, 2006). It is unfortunate that, developing healthy sexuality in adolescence has been replaced by concerns on the risks that are associated with early and unsafe sexual activity (Kelly, 2001).

Forth, Tanzania has continued losing a lot of energetic human resources due to HIV/AIDS pandemic. Machira of The Citizen (Sunday, 22 April, 2012) reported that, although Tanzania, like the rest of the world, has made remarkable progress in taming the HIV/AIDS pandemic, the country still ranks high globally in the number of deaths caused by the deadly virus. Using 2009 figures, he reported that, the US Central Intelligence Agency (CIA) ranks [Tanzania] number four in a new report, with an annual estimate of 86,000 deaths, which makes it lead in the East African Community (EAC), in the number of victims dying from the scourge and associated diseases. This is a critical issue that has to be tackled from all angles of human development.

Therefore, it is absurd to impound our thinking on adolescents' sexual activity, without taking measures to rescue them from the risks associated to it. Needless of studies, the most important thing needs to be addressed is how positive changes are to be achieved by rising academic performance of schoolchildren and preventing them from HIV infections and premarital pregnancy. Although efforts are made to solve these problems, it seems investing in human through education is hampered by an increase in dropouts due to students' truancy, pregnancy as the results of involvements in sexual activity, and other reasons of a sort.

\subsection{Objectives}

Consequently, this study aimed to solicit information of what efforts schoolgirls put forwards to prevent themselves from unplanned-premarital-pregnancies, to improve academic performance. To accomplish these aims, it sought to: 1) examine schoolgirls' knowledge of sexual activity, 2) explore schoolgirls' engagement in sexual activity, 3) examine schoolgirls' efforts towards preventing pregnancy, and 4) investigate schoolgirls' views towards sexual activity.

\section{Methodology}

\subsection{Participants}

Ninety six schoolgirls from two districts participate in this study. Forty five of them in three secondary schools in a coastal district (Bagamoyo) were requested to participate in this study by completing a questionnaire; and 15 of these, in one school were covertly observed. In an upcountry district (Shinyanga), 51 schoolgirls in five secondary schools were requested for focus group interviews. Participants from Bagamoyo were drawn from form three and five while in Shinyanga, were all form three students. The ages of participants were between 14 
and 22 years.

\subsection{Instruments and Procedures}

The study was designed in a pragmatic approach. Data were collected using questionnaire and covert observation (coupled with social conversations with teachers and classmates of the observed students)-in Bagamoyo; and focus group interviews-in Shinyanga. The researcher distributed and collected the questionnaires personally with help of regular teachers. The questionnaire comprised of both closed and open-ended questions, which required students to state their experience of, and involvement in, sexual activity. Covert observation was done by the researcher (Note 1); this intended to triangulate the data obtained through questionnaire. The researcher observed 15 students in different incidences including night preparation time (in Tanzania commonly known as 'prep time'), graduation ceremony, disco day, and other social events at school. On the other group in Shinyanga, the researcher did focus group interviews. Each focus group interview comprised 10 schoolgirls except one that consisted of 11 , and the average time to conduct one focus group interview was one hour. The focus group interview guide was prepared highlighting main issues for the discussion.

\subsection{Data Analysis}

Data obtained from questionnaire were mostly in form of written texts. These data were summarised and presented as paraphrases in a thematic format. Focus group interviews produced voice data. These voices were transcribed into texts and summarised for analysis. Observation data were summaries, which were used to supplement the data from questionnaire. All the data were presented in relation to their contribution to the four themes under this study. The themes are knowledge of sexual activity, engagement in sexual activity, efforts to prevent risky sexual activity and pregnancy, and views towards sexual activity.

\section{Results and Analysis}

\subsection{Knowledge of Sexual Activity}

In this study knowledge of sexual activity refers to the participants' ability to describe, identify, and/or define activities involved in sexual activity. Focus group interview guide was prepared to assess if schoolgirls have knowledge of sexual activity and on the other hand the questionnaire tested students' ability to identify existence of sexual activity in their schools. Data from both questionnaire and focus group interviews showed that schoolgirls know the basics of sexual activity. Schoolgirls in Shinyanga were able to define what sexual activity is, and identify activities related to it. The common definition given in all five focus groups, in Shinyanga, was that, sexual activity involves relationship between two people of opposite sex who make love and other related activities for pleasure and/or marriage. They made it clear that, sexual activity involves insertion of a male's penis into a female's vagina. They mentioned other activities related to it such as kissing, romantic body touching; though kissing were regarded sexual activity, only if it involves sexual partners. In Bagamoyo, schoolgirls were able to identify the existence of sexual activity by exemplifying the 
existence of heterosexual relationships involving students. They mentioned the existence of sexual relationships between schoolgirls and teachers as well as between schoolgirls and schoolboys.

However, both coastal and upcountry schoolgirls associated sexual activity with heterosexuality-the sexual orientation toward people of the opposite sex (Passer \& Smith, 2004)-or penetrative sexual intercourse rather than homosexuality-the sexual orientation toward people of the same sex (Rathus \& Nevid, 1992; Passer \& Smith, 2004)-like gays and lesbians which they termed it 'dirty practice'. Although they did not accept homosexuality as sexual activity, they were able to describe who the homosexuals are, and how homosexuality is practised, which indicated their knowledge of sexual activity. This knowledge is however questionable if it helps them to overcome the sexual activity pressures from the community and prevent themselves from unplanned-premarital-pregnancies. Studies showed that control over sexuality is gendered in such a way that it gives girls less power than boys over their sexuality (Haren, 1999).

\subsection{Engagement in Sexual Activity}

Schoolgirls were required to indicate or say if they engage in sexual activity. Data from questionnaire showed that no respondent was in sexual relationship; however, they mentioned existence of sexual relationships which involved students in their schools. Through researcher's observation, it was clear that many observed schoolgirls were in sexual relationships with either a schoolboy or a teacher at school or other persons outside the school. Schoolgirls' unwillingness to expose their sexual relationships and mention others may have happened because many are likely to project unacceptable behaviours to others. Projection is a popular concept in everyday discourse as well as in psychological thought; it refers to seeing or thrusting of one's own traits or unacceptable impulses onto other people (Rathus \& Nevid, 1992; Baumeister, Dale, \& Sommer, 1998).

On the other hand, data from focus group interviews showed that some respondents have had sex intercourse with someone in their life time and were in sexual relationship in the time of this study. They also mentioned, at school, sexual relationships are rampant and taken as fashion to comply with groups (peer pressure), satisfaction of body sexual desire, and getting gifts. Gifts were the main blinding instruments for girls to go into sexual relationships. Boys initiate the relationships and girls accept if they feel like going into; however, in many cases, schoolgirls accept because schoolboys or sometimes male teachers were too insistent. The schoolgirls, in Shinyanga, added that in our cultures, girls do not initiate sexual relationships; but, there are situations where some girls indirectly seduced boys for sexual activity.

\subsection{Efforts against Risky Sexual Activity and Pregnancy}

In this study schoolgirls were asked to say what they do to prevent themselves from sexual activity. In both coastal and upcountry, schoolgirls identified self-awareness as the most effective way to help them do away with all kinds of sexual activity. It was insisted that, schoolgirls should know themselves and their goals in schools and focus on academic activities. Further, avoidance of risky groups that may pressure a schoolgirl into sexual 
activity was mentioned in Shinyanga; risky groups refer to students who are involved in drinking alcohol, smoking marijuana or bhang, and participating in other notorious or indiscipline behaviours. Additionally, schoolgirls mentioned avoiding risky situations like walking alone during nights, going to disco and bar, etc. Moreover, working hard and exercising were mentioned and emphasised that schoolgirls should work hard in all activities and when ample time is available they should use it for body (physical) exercises. And, lastly, reporting the unwelcomed sexual intention of boys or teachers to parents or teachers was suggested.

It was learned however, that reporting unwelcomed sexual intentions of boys or teachers to teachers-male teachers in particular-was a challenge for schoolgirls. One schoolgirl, in Shinyanga, narrated that,

"Sometimes you may wish to report sexual violence [unwelcomed sexual request] to your teacher [referring to male teachers in particular] and you find that the same teacher asked you the other days to be in sexual relationship with him... reporting to him is like providing an opportunity for him to either have you or punish you. At least female teachers can help or listen to our problems."

This narration implies a lot regarding sexual activity issues in schools as well as barriers schoolgirls encounter in their efforts against sexual activity or unplanned pregnancy. Schoolgirls, apart from experiencing hurdles of sexual pressures from schoolboys and some of their teachers, they too face barriers to seeking for help and support from their male teachers. It was added that, even community leaders do not help students in issues related to sexual activity as it was noted from the interviews that:

"Even leaders in our community do not care about this... it normal and common to them... but, when a schoolgirl becomes pregnant, they will point fingers at her... that is the reality in our community".

The issue of preventing schoolgirls from unplanned-premarital-pregnancies was discussed. Schoolgirls mentioned what girls can do to prevent pregnancy. Although it was difficult to directly tap what respondents themselves do, it could be read from their suggestions. Three ways were suggested: the use condoms, the use hormonal implants or drugs, and avoiding penetrative sex on danger dates-when a female is likely to conceive when a male ejaculate his sperms in the vagina.

It was unfortunate however that these ways were difficult for most schoolgirls. The use of condoms for example, has to be decided by the male partner. If the male partner does not have the condom or does not want to use it, most girls have no option other than giving in to the practice. There is also a negative attitude towards associated to condom use among girls as it is believed that condoms are psychological tranquillisers. It was also learned from respondents that, they did not support the use of condom due to their religious orientations. Secondly, the use of hormonal implants or drugs was seen as very difficult to many as it involves seeking medical and clinical prescriptions and it was viewed to have cost 
implications. Lastly, avoiding penetrative sex on danger dates was also a difficult as most girls are not aware of those days and even if they are, the sexual desires overwhelm them as one schoolgirl commented:

"When you feel sex, you forget everything; you don't even think you are a student or in danger dates. What is in your mind is to quench your sex thirst".

\subsection{Views towards Sexual Activity}

Schoolgirls were asked to give their views towards sexual activity in schools. A variety of views was given and for the purpose of this study the views were categorised into three and analysed as follows:

The first category was that, most of respondents viewed sexual activity, in schools, as dirty practices stamped with full of cheating between partners. Schoolgirls said that, to them, it is not the right time to practise sexual activity. They added, most students, who practise sexual activity find themselves into risks of unplanned-premarital-pregnancies, sexually transmitted diseases, poor academic performance and dropping out of school. It is an activity to be done after school life as one student insisted,

"We can do, but at a right time... We need to concentrate on studies and wait till we get employed... or when we get married we will enjoy all these freely without any worries".

The second category of schoolgirls' views was that, some students viewed sexual activity in schools as a form of sexual violence or exploitation, especially, when teachers or adults have sexual relationships with schoolgirls. It was said that some teacher give favours to schoolgirls in exchange of sex and harass others especially those who reject their sexual intentions. Some schoolgirls go into sexual relationships with their teacher because they fear to be failed by the teacher if they reject him. One schoolgirl insisted.

"It is a big challenge for girls; everyman wants to have sexual intercourse with us... we are asked for sex in the streets where we live; at school, our fellow schoolboys ask us for sex, and worse is, even some of our male teachers ask for sexual relationship with us".

The last category of schoolgirls' views to sexual activity in schools was that, very few students viewed sexual activity as a form of entertainment. One schoolgirl said, "Sometimes, when you are tired and meet your boy you enjoy and relax". This statement meant that sexual activity is enjoyable and relaxing and some students use it to entertain themselves. This view is consistent with Kelly's contention that all over the world, young people are starting to have sex earlier and they value their sexual pleasure more than safer sexual practices (Kelly, 2001). This also is true for Tanzanian students, because many studies have found that students practice sexual activity (Petro, 2009). However, it is unfortunate that a significant number of students end in unplanned-premarital-pregnancies or dropping out of schools. Kelly adds that adolescents typically do not have access to the kinds of sex education that will accurately inform and aid them in developing the necessary skills to manage their sexual decisions and 
help them to recognise the responsibilities that go along with sexual behaviours (Kelly, 2001).

In this study, it was discovered that there were many students practising sexual activity. For example, in Shinyanga, some respondents said that they practise and in all focus group interviews existence of sexual activity in schools was said to be rampant and students are happy with the situation. It was also said that, some of schoolgirls were in sexual relationships with their teachers and they were happy. Though respondents said, some of their fellow students were happy being in sexual relationships with teachers, this is unlawful, unacceptable, and violation schoolgirls' rights as students, which is a form of sexual exploitation in schools.

\section{Discussion}

The results of this study show that majority of schoolgirls who took part in this study from both coastal and upcountry districts were knowledgeable on sexual activity though not very deep. The results also show that the majority of schoolgirls were sexually active engaging in sexual activity regardless the dangers or risks associated to it. Moreover, the results show that schoolgirls who participated in this study know many ways to prevent themselves from risky sexual activity and unwanted-premarital-pregnancy; however, they were not making use of them. And further, results reveal that the participants viewed sexual activity differently, whereas majority viewed as dirty practices, some viewed as forms of sexual violence or exploitation, and few viewed as entertainment-something to enjoy.

Regarding schoolgirls' knowledge of sexual activity not being deep, studies show that, in Tanzania, a few aspect of sexuality education, particularly in the area of HIV/AIDS are covered in the national school curriculum; its delivery focuses on knowledge, and little attention is paid to the other aspects like skills, relationships, attitudes and values; and its greater part is covered during secondary education level, which is arguably too late given that sexuality education works effectively if it is provided early before young people reach puberty (Mkumbo, 2009).

The results of this study also show that schoolgirls lack negotiating power in sexual relationships, which necessitate for their sexual exploitation from schoolboys and other adult men including their male teachers. Adolescents, particularly young girls, sometimes are forced to practise sexual activity through sexual exploitation, which is common within educational institutions in much of Africa (Mgalla, Schapink, \& Boerma, 1998). Other studies show that, female youths do not have strong negotiating powers over their bodies and sexual relationships (Haren, 1999; Philemon \& Kessy, 2008). It is unfortunate that schoolgirls are exploited sexually by people they can trust especially their teachers.

\section{Conclusion and Recommendations}

It is clear that students have the basics of what sexual activity is. In addition to their 
knowledge of sexual activity, there are a significant number of students who practise sexual activity among themselves or with other people including teachers, adults [sugar daddies or mammies], or youths outside the academic realm. It is unwise to see this as normality but, measures need to be taken. Unless students are provided with proper sex and sexuality education they may approach sexual activities unrealistically and without careful consideration of the dangers and risks involved (Kelly, 2001). Therefore, parents should take consideration on their children; the community has to play its part by mentoring youths on the right ways. Self awareness is very important for schoolgirls, and sex education should be given to them and all people in the community emphasising on self control, abstinence, fidelity and faithfulness. Policy makers and other stakeholders in Tanzania have to shoulder the responsibilities of helping schoolgirls to get the best out of their adolescence.

\section{References}

AIDS Info (August, 2012). HIV and its treatment. Fact Sheets. Retrieved from http://www.aidsinfo.nih.gov/contentfiles/HIVandItsTreatment_cbrochure_en.pdf

Baber, C. M. (2005). Adolescents' sexuality. UNH Centre on Adolescence. Retrieved from http://www.chhs.unh.edu/sites/chhs.unh.edu/files/docs/fs/adolescent_resources/Adolesce nt_Sexuality.pdf

Baumeister, R. F., Dale, K., \& Sommer, K. L. (1998). Freudian Defense Mechanisms and Empirical Findings in Modern Social Psychology: Reaction Formation, Projection, Displacement, Undoing, Isolation, Sublimation, and Denial. Journal of Personality, 66(6), 1081-1095. Main Street, Malden: Blackwell Publishers. Retrieved from http://faculty.fortlewis.edu/burke_b/personality/readings/freuddefense.pdf

Campbell, C., \& MacPhail, C. (2002). Peer education, gender and the development of critical consciousness: Participatory HIV prevention by South African youth. Social Science and Medicine, 55(2), 331-345. Retrieved from http://eprints.lse.ac.uk/385/1/801ssm5-final-revision.pdf

Evans, R. (2002). Poverty, HIV, and barriers to education: Street children's experiences in Tanzania. Gender and Development, 10(10), 51-62. Retrieved from http://www.jstor.org/discover/10.2307/4030546

Haren, J. (1999). Girls in search for love, sex and money: A study on adolescent sexuality in an urban Tanzanian neighbourhood. Occasional Paper 93. Retrieved from http://www.socsci.ru.nl/maw/cidin/bamaci/scriptiebestanden/303.pdf

Hayes, C. D. (1987). Risking the future: Adolescent sexuality, pregnancy, and childbearing. National Academy of Sciences. Retrieved from http://www.nap.edu/catalog/948.html

Hope, R. (2007). Addressing cross-generational sex: A desk review of research and programs. Population Reference Bureau. Retrieved from http://www.prb.org/igwg_media/AddressingCGSex.pdf 
Kelly, G. F. (2001). Sexuality today: The human perspective. Boston: McGraw Hill.

Machira, P. (Sunday, $22^{\text {nd }}$ April, 2012). Why Tanzania ranks highly in HIV/AIDS deaths. The Citizen. Retrieved from http://www.thecitizen.co.tz/sunday-citizen/40-sunday-citizen-news/21718-why-tanzania -ranks-highly-in-hivaids-deaths.html

Mgalla, Z., Schapink, D., \& Boerma, J. T. (1998). Protecting schoolgirls against sexual exploitation: A guardian programme in Mwanza, Tanzania. Reproductive Health Matters, 6(12), 19-30. http://dx.doi.org/10.1016/S0968-8080(98)90004-0

Mkumbo, K. A. (2009). Content analysis of the status and places of sexuality education in the national school policy and curriculum in Tanzania. Educational Research and Review, 4(12), 616-625.

Mkumbo, K., \& Tungaraza, F. D. (2007). Parents' views and attitudes towards school based sex and relationships education in rural and urban Tanzania. Papers in Education and Development, 27, 171-188. Dar es Salaam: DUP.

Passer, M. W., \& Smith, R. E. (2004). Psychology: The science of mind and behaviour. New York: McGraw Hill.

Petro, B. (2009). Teachers' views and attitudes towards adolescents who are involved in sexual relationships in Tanzanian secondary schools. Dar es Salaam. DUP. Unpublished MA Dissertation.

Philemon, J. R. M., \& Kessy, S. S. A. (2008). Negotiating safe sex among young women: The fight against HIV/AIDS in Tanzania. Research Report, Dar es Salaam: REPOA.

Rathus, S. A., \& Nevid, J. S. (1992). Adjustment and Growth: The challenges of life. Florida: Holt, Rinehart and Winston.

Santrock, J. W. (2006). Life-span development. Boston: McGraw Hill.

Shemdoe, A. I. (2005). Attitude of parents towards sexual socialization of adolescents: A case study of the Zaramo tradition - Kisarawe. Dar es Salaam: DUP. Unpublished M.A. Dissertation.

Tanzania Commission for AIDS (TACAIDS), Zanzibar AIDS Commission (ZAC), National Bureau of Statistics (NBS), Office of Chief Government Statistician (OCGS) \& Macro International Inc. (2008). Tanzania HIV/AIDS and malaria indicator survey 2007-08. Dar es Salaam, Tanzania: TACAIDS, ZAC, NBS, OCGS and Macro International Inc.

The United Republic of Tanzania - MoEVT. (2010). Basic education statistics in Tanzania (BEST) 2006-2010: Revised national data. Dar es Salaam: Author.

The United Republic of Tanzania - Prime Minister's Office. (2001). National policy on HIV/AIDS. Dar es Salaam: Author.

Walcott, C. M., Meyers, A. B., \& Landau S. (2007). Adolescent sexual risk behaviors and 
school-based sexually transmitted infection/HIV prevention. Psychology in the Schools, 45(1), 39-51. http://dx.doi.org/10.1002/pits.20277

\section{Note}

Note 1. The researcher taught at one of the sampled schools for more than six months during data collection. Therefore, it was easy to observe some of the students in different events at that particular school.

\section{Copyright Disclaimer}

Copyright reserved by the author(s).

This article is an open-access article distributed under the terms and conditions of the Creative Commons Attribution license (http://creativecommons.org/licenses/by/3.0/). 